\title{
Utilización de Células Troncales en Reconstrucción Cráneo-Maxilo-Facial en Humanos
}

\author{
Stem Cells in Human Cranio-Maxillo-Facial Reconstruction
}

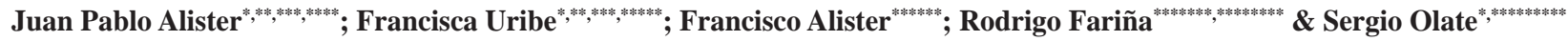

ALISTER, J. P.; URIBE, F.; ALISTER, F.; FARIÑA, R. \& OLATE, S. Utilización de células troncales en reconstrucción cráneomaxilo-facial en humanos. Int. J. Morphol., 34(4):1531-1538, 2016.

RESUMEN: El propósito de este estudio fue evaluar la evidencia en relación al empleo de técnicas reconstructivas en el área cráneo-facial asociado el uso de células troncales en humanos. Se realizó una revisión sistemática de la literatura en las bases Medline, ScienceDirect, EMBASE, TripDatabase, LILACS entre marzo del 2004 a marzo del 2016 con criterios de elegibilidad y estrategia de búsqueda definida. La selección de artículos fue realizada por dos investigadores de forma independiente y cuando ellos presentaron discordancia, un tercer investigador realizó le selección. Se encontraron un total de 382 artículos, se realizó una selección de artículos, eliminado duplicados, estudios experimentales en animales y selección según análisis de resúmenes, se seleccionaros 14 artículos con procedimientos reconstructivos en el área cráneo-facial asociado a células troncales. Existe limitada evidencia de calidad en relación a la utilización de células troncales en reconstrucción cráneo facial en humanos. A excepción de un estudio (ensayo clínico de bajo nivel de evidencia), todos corresponden a series o reporte de casos, con lo cual no es posible recomendar su utilización en procedimientos reconstructivos. Es necesario realizar estudios de evidencia sustentable con el empleo de células troncales que permitan identificar su real rendimiento al compararlo con otras técnicas quirúrgicas.

PALABRAS CLAVE: Células troncales; Reconstrucción; Ingeniería de tejidos; Cirugía craneofacial.

\section{INTRODUCCIÓN}

Desde que en 1960 Friedenstein et al. aislaron las primeras poblaciones celulares provenientes de la médula ósea, y que pudieron formar colonias logrando la diferenciación hacia osteoblastos (Friedenstein et al., 1970; Khojasteh et al., 2012), la cirugía reconstructiva cráneo-facial se ha dedicado a investigar el potencial uso de las técnicas de ingeniería tisular para lograr reconstrucciones biológicamente funcionales y más predecibles. Actualmente existen diversas técnicas para reconstruir defectos en el área maxilofacial, entre estos están los injertos libres, los injertos microvasculares, los injertos de banco y la distracción osteogénica; sin embargo la morbilidad de las cirugías, la necesidad de sitio donante y la poca cantidad de aporte de tejido óseo son factores a considerar en su indicación (Navarro-Vila et al., 2002; Pogrel et al., 1997 \& Fariña et al .2016).
Las células troncales son un grupo heterogéneo de células multipotenciales, auto-renovantes, que poseen competencias clonogénicas y la capacidad de diferenciarse en líneas celulares de tejido mesenquimal y conectivo. Células troncales se pueden aislar y caracterizar de diferentes tejidos y fluidos, tales como médula ósea, sangre periférica, sangre de cordón umbilical, placenta, fluido y membrana amniótica, tejido adiposo, dermis, folículos pilosos, membrana sinovial, pulpa dental, saco pericoronario, encía, ligamento periodontal, músculo esqueletal, sistema nervioso central, bulbo olfatorio, retina, entre otros (Machado et al., 2012). Se han publicado diferentes artículos acerca el potencial uso de ésta técnica para reparación tisular en diversas partes del organismo, incluyendo el uso en reconstrucción cráneo-facial, esto debido a que generalmente las cirugías resectivas en el territorio

* División de Cirugía Oral y Maxilofacial, Universidad de La Frontera, Temuco, Chile.

** División de Cirugía Maxilofacial, Hospital Hernán Henríquez Aravena, Temuco, Chile.

*** Programa Doctorado en Ciencias Médicas, Facultad de Medicina, Universidad de La Frontera, Temuco, Chile.

**** Becario CONICYT-PCHA/Doctorado Nacional/ 2015-21150598.

****** Becario CONICYT-PCHA/Doctorado Nacional/2015-21150752.

******* Programa de Doctorado en Ciencias de la Ingeniería, Pontificia Universidad Católica de Chile, Santiago, Chile.

******** Unidad de Cirugía Maxilofacial, Hospital del Salvador, Santiago, Chile.

********* Departamento de Cirugía y Traumatología Maxilofacial, Facultad de Odontología, Universidad de Chile, Santiago, Chile.

********* Centro de Investigación en Ciencias Biomédicas, Universidad Autónoma de Chile, Chile 
maxilofacial implican pérdida de tejidos duros y blandos. En este campo la ingeniería tisular se presenta como un campo interdisciplinario en que la aplicación de conceptos médicoquirúrgicos y de ingeniería hacia el desarrollo de sustitutos biológicos para recuperar, mantener y mejorar los tejidos perdidos y lograr ser una alternativa a los auto y aloinjertos para la regeneración de las estructuras perdidas (Li et al., 2005; Shanti et al., 2007).

El objetivo de este artículo es realizar una revisión sistemática para identificar las aplicaciones de las células troncales en la reconstrucción cráneo-facial en estudios realizados en humanos.

\section{MATERIAL Y MÉTODO}

Se realizó una revisión sistemática para responder a la pregunta: ¿Existe aplicación validada de las células troncales en la reconstrucción ósea cráneo-facial en humanos?. La búsqueda de literatura científica identificó artículos en los que se realizaron procedimientos quirúrgicos de reconstrucción en el área cráneo-maxilo-facial, en humanos, utilizando dentro de los procedimientos técnicas de cultivo celular.

Criterios de elegibilidad: Los criterios de inclusión fueron los siguientes: 1) artículos publicados en ingles, español y portugués 2) artículos que incluyeran procedimientos reconstructivos cráneo-faciales asociados a cultivo celular, 3) grupo de estudios en seres humanos, 4) diseños de estudio considerando series de casos, estudios retrospectivos, prospectivos, 5) artículos publicados entre Marzo de 2004 a Marzo de 2016. Se excluyeron estudios experimentales, cuasi experimentales o que fueran realizado en animales de experimentación. La selección de artículos fue realizada por dos investigadores de forma independiente; cuando existió controversia y diferencias en la aplicación de criterios, un tercer investigador realizó el análisis y final determinación para la incorporación o exclusión en el estudio.

Estrategia de Búsqueda: Las bases de datos empleadas incluyeron MEDLINE, LILACS, EMBASE, ScienceDirect y Trip Database; se realizó una búsqueda sistemática, sensible en la que se utilizaron términos MeSH y términos libres. Posteriormente se realizó una búsqueda específica en la que se añadieron términos booleanos (AND/OR). Los límites fueron estudios en humanos realizados entre Marzo del 2004 y Marzo del 2016. El algoritmo de búsqueda en la base de datos MEDLINE fue: ((human) OR "Adult"[Mesh])) AND (((((stem cell) OR stem cells) OR pluripotent stem cells) OR mesenchymal stem cells) OR
("Adult Stem Cells"[Mesh] AND "Stem CellResearch"[Mesh]))) AND ((((craniofacial surgery) OR craniofacial reconstruction) OR maxillofacial reconstruction) OR "Surgery, Oral"[Majr]).

Adicionalmente se revisó la lista de referencias de los estudios seleccionados para la investigación. El análisis de sesgos se realizó con la herramienta propuesta como PRISMA (Liberati et al., 2009).

\section{RESULTADOS}

Se encontraron 382 artículos en las bases de datos MEDLINE, LILACS, EMBASE, ScienceDirect y Trip Database (Fig. 1). Luego de eliminar los artículos duplicados, se realizó una revisión de los resúmenes dejando los artículos que aportaban información a la revisión. Se seleccionaron y revisaron en extenso un total de 50 artículos que aportaban información en relación a procedimientos reconstructivos en el área cráneo-maxilo-facial utilizando técnicas de cultivo celular. Se encontraron 14 artículos con reportes clínicos donde se utilizaron técnicas de cultivo celular para reconstrucción del territorio cráneo- facial en humanos (Tabla I).

En relación a los trabajo excluidos, éstos principalmente correspondían a estudios experimentales en animales (ratas, conejos, porcinos, perros) y a investigaciones de laboratorio. Solo un ensayo clínico (de bajo nivel evidencia) fue seleccionado (Rickert et al., 2011), evaluando la reconstrucción de seno maxilar mediante aloinjertos y células troncales. Los otros artículos corresponden a reporte y series de casos donde principalmente se evalúa clínicamente (complicaciones quirúrgicas, cicatrización tejidos blandos, imagenología)

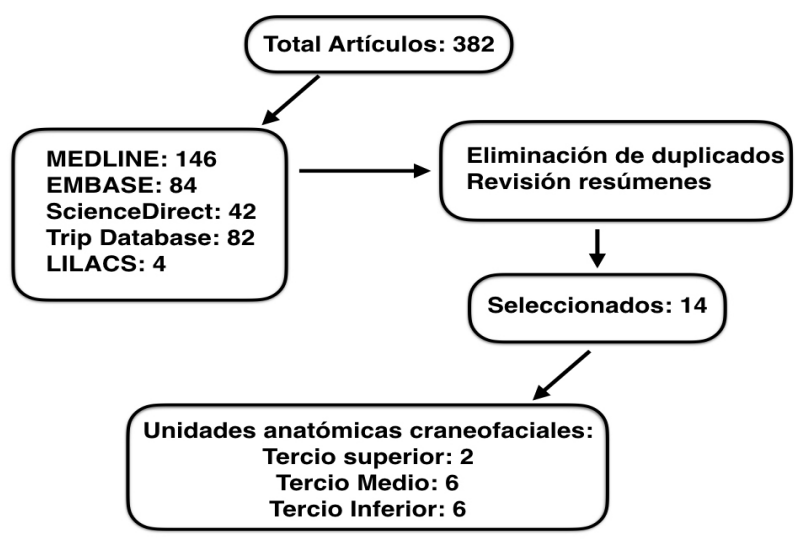

Fig 1. Flujograma de la selección de artículos y estrategia de búsqueda 


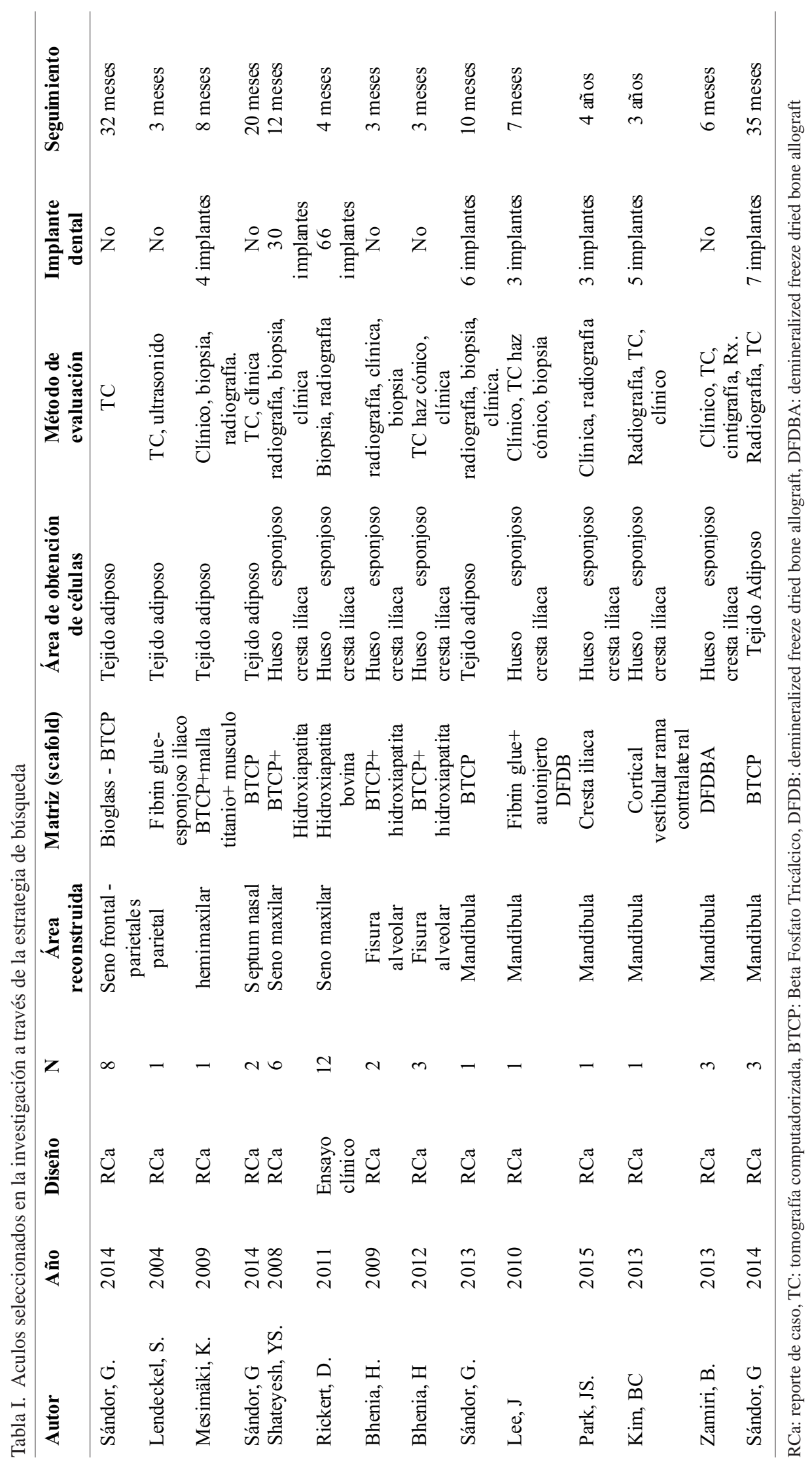

y en menor cantidad biopsia e histomorfometría de las zonas injertadas (Sándor et al., 2014; Lendeckel et al., 2004; Mesimäki et al., 2009; Behnia et al., 2012; Sándor et al., 2013; Zamiri et al., 2013; Lee et al., 2010; Park et al., 2015; Kim et al., 2013).

El análisis histológico e histomorfométrico se llevó a cabo en los casos donde se instalaron implantes dentales posterior a la reconstrucción ósea (Mesimäki et al., Shayesteh et al., 2008; Rickert et al., Sándor et al., 2013; Zamiri et al.), a excepción de un caso de fisura alveolar donde se tomó una biopsia directamente sin insertar un implante (Behnia et al., 2009). En relación al "scaffold" o matriz de soporte empleada, la utilización del Beta Fosfato Tricálcico fue el más utilizado(Sándor et al., 2014; Mesimäki et al., Shayesteh et al., Behnia et al., 2009; Behnia et al., 2012; Sándor et al., 2013), esto debido a su tasa de reabsorción, su potencial de manipulación y porosidad.

La zona dadora más utilizada para el cultivo celular fue la zona esponjosa de la cresta ilíaca (Shayesteh et al.; Rickert et al.; Behnia et al., 2009; Behnia et al., 2012; Lee et al.; Park et al.; Kim et al., 2013), seguida del tejido adiposo (Sándor et al., 2014; Lendeckel et al., 2004; Mesimäki et al.; Sándor et $a l$.$) ; la cresta ilíaca permite$ cultivo directo de células precursoras de osteocitos, en cambio la utilización de tejido adiposo como zona donante de células troncales se utilizaría por su facilidad de acceso y recolección. 


\section{DISCUSIÓN}

Observaciones en Células Troncales. Muchos reportes de casos han mostrado que el cultivo de células mesenquimales pluripotenciales puede reemplazar el "gold standard" para reconstrucción ósea (autoinjertos libres o microvasculares) por lo que lo han denominado como el "platinum standard" de la reconstrucción ósea, mediante la utilización de células mesenquimáticas pluripotentes junto a una matriz (scaffold) reabsorbible para inducir osteogénesis (Soltan et al., 2005).

Fenotípicamente las células troncales mesenquimáticas (MSC: Mesenchymal Stem Cells) se caracterizan por ser células adherentes, con morfología fibroblastoide que expresan marcadores como CD29, CD44, CD90, CD105, ASMA, vimentina pero no expresan marcadores de células hematopoyéticas como CD14, CD34, CD45; sintetizan elementos de matriz extracelular como colágeno tipo I, fibronectina, laminina, versicán, citoquinas como IL-1, 6, 7, 8, 11, 12, 14, 15, LIF, SCF, G-CSF, GM-CSF, MCP-1, SDF-1 y factores de crecimiento como bFGF, VEGF, BDNF, NGF (Horwitz et al., 2005); . A pesar de estos conocimientos, hasta la fecha no se ha reconocido ningún marcador como selectivo de las MSC, en consecuencia el "gold standard" para caracterizarlas sigue siendo la evaluación del potencial de diferenciación a los linajes mesenquimáticos adiposo y osteogénico (Giordano et al., 2007).

Propiedades intrínsecas de las células troncales son su capacidad de autorrenovarse y su potencial de diferenciarse, al menos a un tipo de célula madura. Las células troncales adultas (ASC) se obtienen desde diferentes órganos y tejidos como por ejemplo: piel, hígado, intestino, corazón, riñón y médula ósea. En esta última, residen las células troncales hematopoyéticas (HSC) y las células troncales mesenquimáticas (MSC). Ambas, se consideran células troncales multipotentes ya que generan un amplio repertorio de células maduras. Por ejemplo, las HSC dan origen a todas las células sanguíneas y a células endoteliales. Las MSC dan origen a células mesenquimales como las del estroma hematopoyético, adipocitos, condrocitos, osteocitos y miocitos (Minguell et al., 2001; Hristov et al., 2003).

Recientemente se ha demostrado que las MSC tienen plasticidad es decir, también pueden generar células de linajes distintos a su origen germinal. Así, a partir de MSC pueden obtenerse: neuronas, astrocitos, oligodendrocitos, células endoteliales, neumocitos, células de la piel, productoras de insulina y renales (Rojas et al., 2005; Nakagawa et al., 2005; Moriscot et al., 2005). La plasticidad de las MSC, al igual que la de otras ASC, se asociaría al menos a alguno de los siguientes mecanismos biológicos: 1) transdiferenciación, en cuyo caso se inactivaría la vía de diferenciación a los linajes mesenquimáticos y se activaría la vía de diferenciación propia de otros linajes, 2) des-diferenciación, tal que las MSC retornarían a una célula más troncal que luego se comprometería a un linaje distinto al mesenquimático, 3) contaminación de las MSC con ASC de otros linajes, por ejemplo MSC contaminadas con HSC, 4) presencia de ASC pluripotentes en los cultivos de MSC, por ejemplo células progenitoras adultas multipotentes (MAPC) las cuales se ha descrito pueden diferenciarse a cualquier tipo celular, 5) artefactos como fusión celular (Herrera et al., 2004; Li et al.; 2004; Ratajczak et al., 2004).

La investigación de células troncales representa una gran oportunidad en el área de medicina reconstructiva; en el área cráneo-maxilo-facial, representa una herramienta para poder reconstruir tanto tejidos duros como blandos perdidos por trauma, tumores o anomalías congénitas. La arquitectura facial esta compuesta por diferentes tejidos agrupados en unidades anatómicas complejas que otorgan al individuo la capacidad de interactuar con el medio, de alimentación, audición, olfato, etc. Cuando son afectadas estas estructuras, se producen severas alteraciones que tienen asociadas grandes cicatrices, desfiguramiento e importantes secuelas psicológicas (Tollemar et al., 2016). Si bien la cirugía progresó de forma significativa en el área reconstructiva con desarrollo de la transferencia microvascular de tejidos y nuevas técnicas de injerto óseos, todavía se mantiene como puntos desfavorables la necesidad de sitios donante con su consecuente morbilidad, así como los resultados de dichas reconstrucciones.

Estudios en Procesos Reconstructivos Cráneo-MaxiloFaciales. En relación a la reconstrucción del tercio superior y cráneo, éste representa un gran desafío ya que en una gran mayoría de los casos son realizadas por trauma (lo que involucra gran pérdida de tejido) o en niños con alguna alteración del desarrollo o con complicaciones derivadas de tumores, lo que implica una reconstrucción capaz de mantener el normal desarrollo craneal. Generalmente estos defectos son reconstruidos con hueso autólogo o biomateriales como biopolímeros, implantes de polietileno, hueso demineralizado, hidroxiapatita, entre otros. Estos sustitutos tiene riesgos propios como la morbilidad del sitio donante y la cantidad de material en los autoinjertos; y el riesgo de infección y exposición en los biopolímeros; junto a esto la imposibilidad de crecer en menores de edad (Tollemar et al.; Chung et al., 2012). La reconstrucción de estos defectos utilizando matriz (scaffolds) biodegradable junto a células cultivadas in vitro tendrían los efectos beneficiosos de cubrir una gran área de tejidos, sumado a su potencial de crecimiento que no interferiría con el desarrollo normal en menores de edad (Lendeckel et al.). 
En relación a la reconstrucción del tercio medio facial, se han publicado artículos principalmente en elevación de seno maxilar (02 artículos), reconstrucción de reborde alveolar (01 artículo) y fisura labio-alveolo palatina (02 artículos). La utilización de mallas de titano asociada a Bfosfato tricálcico + BMP y células troncales ha mostrado resultados interesantes en grandes reconstrucciones de hemimaxilares post resección, sin embargo no hay ensayos clínicos que demuestren efectivamente su resultado (Mesimäki et al.; Zuk et al., 2008). En casos de pérdida prematura de piezas dentales antrales, existe una gran reabsorción ósea, con aumento en el volumen interno del seno maxilar, lo que hace muy compleja la instalación de implantes óseointegrados.

Se utilizan muchos sustitutos óseos para la elevación del piso del seno maxilar, sin embargo estos carecen de celularidad y sus potencial osteoinductivo es controversial (Rickert et al.) Los reporte de casos han mostrado buenos resultados, basados en el gran potencial del uso de células troncales mezclado con aloinjertos; esto implica una ventaja al no tener morbilidad de sitio donante, y otorgar las características del hueso autólogo como son osteoinducción y osteogénesis a materiales de relleno sin dichas capacidades (Shayesteh et al.; Zhang et al. 2012; Payne et al., 2014; Rickert et al.).

Las fisuras labio-alveolo palatinas también ha sido un campo de investigación; la reconstrucción clásica de las fisuras alveolares implica autoinjertos, principalmente de tejido esponjoso de cresta iliaca. Se ha explorado el uso de BMP asociado a esponjas de colágeno en el cierre de fisuras con buenos resultados, siendo comparables al autoinjerto de cresta iliaca, así como también la utilización de aloinjertos asociados a matrices de fosfato de calcio y células troncales con reportes de casos con una adecuada reconstrucción del defecto. Sin embargo no existen ensayos clínicos de buena calidad en que se evalúe la calidad de tejidos formados por ambas técnicas. En el promisorio futuro para estos pacientes implicaría menor tiempo de hospitalización, mejor calidad de tejidos duros y blandos y evitar la morbilidad del sitio donante (Behnia et al., 2009; van Hout et al., 2011; Behnia et al., 2012; Payne et al., 2014).

En la reconstrucción de defectos mandibulares existen varios reportes y series de casos que muestran buenos resultados al utilizar técnicas de cultivo celular. Incluso se ha tratado de recolectar células desde los espacios medulares de mandíbula y maxila para evitar la aspiración y recolección celular desde la cresta iliaca, demostrando que se puede obtener igual calidad de células recolectadas, diferenciándose solamente en el tiempo requerido de aspiración para obtener el número mínimo para cultivar (Bu-Kyu et al.,
2011). La reconstrucción mandibular implica un complejo desafío debido a las inserciones musculares y a su biodinámica única en el cuerpo. Se han utilizado mallas de titanio asociadas a biomateriales con B-fosfato tricálcico granulado y BMP para reconstrucciones de segmentos resecados por patología (Payne et al.; Warnke et al., 2006; Zamiri et al.; Sándor et al., 2014). El uso de mallas y biomateriales granulados implica una matriz con propiedades osteconductivas, y que sirven de soporte para las células cultivadas. El sitio donante mas utilizado de células troncales en los artículos evaluados son el tejido esponjoso de la cresta iliaca (Lee et al., 2010; Kim et al., 2013; Park et al.), y por sobre todo, el tejido adiposo (ASC), éste último tiene grandes ventajas debido a la gran cantidad de tejido que se puede recolectar, a la simpleza de la técnica de recolección, la poca morbilidad del sitio donante y la gran capacidad de diferenciación celular hacia línea osteprogenitora, (Grinnemo et al., 2008; Gimble et al., 2006; Chanberlain et al., 2007).

Existen un punto importante en relación a utilización de células troncales para reconstrucción cráneo- facial, este es el tipo de matriz que otorga soporte y el medio de transporte de las células cultivadas. Existen 4 puntos considerados como el concepto de diamante en la regeneración ósea: células osteogénicas, scaffold osteoconductivo, factores de crecimiento y entorno biomecánico. La matriz (scaffold) debe ser un material que idealmente restaure la función, que imite la matriz extracelular, otorgando soporte, resistencia, flexibilidad y capacidad osteoinductiva y osteoconductiva a las células cultivadas sin tener inmunogenicidad. Hollister introduce los cuatro aspectos técnicos fundamentales ideales para una matriz o scaffold: forma, función, fijación y formación (Billström et al., 2013; Hollister et al., 2011).

Los derivados de fosfato de calcio han sido muy estudiados debido a que poseen algunas características deseables como ser osteoconductivos, no tener reacciones inmunológicas, se pueden construir y diseñar manejando su porosidad, forma y resistencia mecánica; así mismo, es un material bioactivo, se puede adherir a los segmentos óseos adyacentes, en contraste con los materiales bioinertes quienes pueden formar una fibro-cápsula indeseable (Egusa et al., 2012; Liu et al., 2014; Zhao et al., 2010; Turhani et al., 2005; Lohberger et al., 2012; Payne et al., 2014). Se han estudiado otros tipos de matrices como fibrina, PRP teniendo buenos resultados, sin embargo una limitante para su utilización sería la menor capacidad de nutrir el cultivo trasplantado, en especial en las zonas centrales de éstos, en comparación con las matrices porosas como el fosfato de calcio que tendría como consecuencia una disminución en la migración y viabilidad celular (Drury et al., 2003; Konopnicki et al., 2015; Khojasteh et al.). 


\section{CONCLUSIÓN}

El futuro de la cirugía reconstructiva cráneo-facial esta dada por el perfeccionamiento de las técnicas de ingeniería tisular, sin embargo existen aspectos que optimizar: 1) las técnicas de recolección de células troncales deben simplificarse junto a medios mas efectivos en diferenciación y multiplicación; 2) el uso de matrices (scaffolds) debe incluir diseños personalizados, de materiales resistentes y similares a la estructura facial perdida integrando actividad osteogénica, y 3 ) el empleo de biomoléculas osteoinductivas como el BMP, que en la mayoría de los artículos revisados juegan un rol fundamental en el éxito de la reconstrucción.

La investigaciones que integran el uso de células troncales en reconstrucción craneomaxilofacial son débiles y se limitan a series de caso; aunque en la mayoría de las publicaciones existe éxito en términos de reconstrucción, no es posible recomendar el uso de células troncales como técnica estándar.

\section{AGRADECIMIENTOS}

Los autores agradecen a la Dirección de Investigación de la Universidad de La Frontera por su financiamiento a través del proyecto DIUFRO DI17-0026.

Los autores Juan Pablo Alister Herdener y Francisca Uribe Fenner desean agradecer a La Comisión Nacional de Investigación Científica y Tecnológica, CONICYT, por financiar sus estudios de Doctorado.

ALISTER, J. P.; URIBE, F.; ALISTER, F.; FARIÑA, R. \& OLATE, S. Stem cells in human cranio-maxillo-facial reconstruction. Int. J. Morphol., 34(4):1531-1538, 2016.

SUMMARY: The purpose of this study was to evaluate the evidence regarding the use of reconstructive techniques in the craniofacial area associated with the use of stem cells in humans. A systematic review of the literature was conducted in the databases Medline, ScienceDirect, EMBASE, TripDatabase, LILACS between March 2004 and March 2016 with eligibility criteria and defined search strategy. The selection of articles was done by two researchers independently and when they presented discordance, a third researcher made the selection. We found a total of 382 articles, made a selection of articles, removed duplicates, experimental studies in animals and selection according to analysis of abstracts, we selected 14 articles with reconstructive procedures in the craniofacial area associated with stem cells. There is limited quality evidence regarding the use of stem cells in the craniofacial reconstruction in humans. With the exception of one study (clinical trial of low level of evidence), all correspond to series or report of cases, with which it is not possible to recommend its use in reconstructive procedures. It is necessary to carry out studies of sustainable evidence with the use of stem cells that allow to identify its real performance when compared with other surgical techniques

KEY WORDS: Stem cells; Reconstruction; Tissue engineering; Craniofacial surgery.

\section{REFERENCIAS BIBLIOGRÁFICAS}

Behnia, H.; Khojasteh, A.; Soleimani, M.; Tehranchi, A. \& Atashi, A. Repair of alveolar cleft defect with mesenchymal stem cells and platelet derived growth factors: a preliminary report. $J$. Craniomaxillofac. Surg., 40(1):2-7, 2012.

Behnia, H.; Khojasteh, A.; Soleimani, M.; Tehranchi, A.; Khoshzaban, A.; Keshel, S. H. \& Atashi, R. Secondary repair of alveolar clefts using human mesenchymal stem cells. Oral Surg. Oral Med. Oral Pathol. Oral Radiol. Endod., 108(2):e1-6, 2009.

Billström, G. H.; Blom, A. W.; Larsson, S. \& Beswick, A. D. Application of scaffolds for bone regeneration strategies: current trends and future directions. Injury, 44 Suppl. 1:S28-33, 2013.

Chamberlain, G.; Fox, J.; Ashton, B. \& Middleton, J. Concise review: mesenchymal stem cells: their phenotype, differentiation capacity, immunological features, and potential for homing. Stem Cells, 25(11):2739-49, 2007.
Chung, M. T.; Liu, C.; Hyun, J. S.; Lo, D. D.; Montoro, D. T.; Hasegawa, M.; Li, S.; Sorkin, M.; Rennert, R.; Keeney, M.; Yang, F.; Quarto, N.; Longaker, M. T. \& Wan, D. C. CD90 (Thy-1)positive selection enhances osteogenic capacity of human adiposederived stromal cells. Tissue Eng. Part A., 19(7-8):989-97, 2012.

Drury, J. L. \& Mooney, D. J. Hydrogels for tissue engineering: scaffold design variables and applications. Biomaterials, 24(24):4337-51, 2003.

Egusa, H.; Sonoyama, W.; Nishimura, M.; Atsuta, I. \& Akiyama, K. Stem cells in dentistry--Part II: Clinical applications. $J$. Prosthodont. Res., 56(4):229-48, 2012.

Fariña, R.; Alister, J. P., Uribe, F. \& Olate, S.; Arriagada, A. Indications of Free Grafts in Mandibular Reconstruction, after Removing Benign Tumors: Treatment Algorithm. Plast. Reconstr. Surg. Glob. Open.15;4(8):e845, 2016 
Friedenstein, A.; Chailakhjan, R. \& Lalykina, K. S. The development of fibroblast colonies in monolayer cultures of guinea-pig bone marrow and spleen cells. Cell Tissue Kinet., 3(4):393-403, 1970.

Khojasteh, A.; Behnia, H.; Dashti, S. G. \& Stevens, M. Current trends in mesenchymal stem cell application in bone augmentation: a review of the literature. J. Oral Maxillofac. Surg., 70(4):972$82,2012$.

Giordano, A.; Galderisi, U. \& Marino, I. R. From the laboratory bench to the patient's bedside: an update on clinical trials with mesenchymal stem cells. J. Cell Physiol., 211(1):27-35, 2007.

Grinnemo, K. H.; Sylvén, C.; Hovatta, O.; Dellgren, G. \& Corbascio, M. Immunogenicity of human embryonic stem cells. Cell Tissue Res., 331(1):67-78, 2008.

Gimble, J. M.; Zvonic, S.; Floyd, Z. E.; Kassem, M. \& Nuttall, M. E. Playing with bone and fat. J. Cell Biochem., 98(2):251-66, 2006.

Herrera, M. B.; Bussolati, B.; Bruno, S.; Fonsato, V.; Romanazzi, G. M. \& Camussi, G. Mesenchymal stem cells contribute to the renal repair of acute tubular epithelial injury. Int. J. Mol. Med., 14(6):1035-41, 2004

Hristov, M.; Erl, W. \& Weber, P. C. Endothelial progenitor cells: mobilization, differentiation, and homing. Arterioscler. Thromb. Vasc. Biol., 23(7):1185-9, 2003.

Hollister, S. J. \& Murphy, W. L. Scaffold translation: barriers between concept and clinic. Tissue Eng. Part B Rev., 17(6):459-74, 2011.

Horwitz, E. M.; Le Blanc, K.; Dominici, M.; Mueller, I.; SlaperCortenbach, I.; Marini, F. C.; Deans, R. J.; Krause, D. S.; Keating, A. \& International Society for Cellular Therapy. Clarification of the nomenclature for MSC: The International Society for Cellular Therapy position statement. Cryotherapy, 7(5):393-5, 2005.

Kim, B. C.; Yoon, J. H.; Choi, B. \& Lee, J. Mandibular reconstruction with autologous human bone marrow stem cells and autogenous bone graft in a patient with plexiform ameloblastoma. $J$. Craniofac. Surg., 24(4):E409-11, 2013.

Konopnicki, S. \& Troulis, M. J. Mandibular tissue engineering: Past, present, future. J. Oral Maxillofac. Surg., 73(12 Suppl.):S13646, 2015.

Lendeckel, S.; Jödicke, A.; Christophis, P.; Heidinger, K.; Wolff, J.; Fraser, J. K.; Hedrick, M. H.; Berthold, L. \& Howaldt, H. P. Autologous stem cells (adipose) and fibrin glue used to treat widespread traumatic calvarial defects: case report. $J$. Craniomaxillofac. Surg., 32(6):370-3, 2004.

Lee, J.; Sung, H. M.; Jang, J. D.; Park, Y. W.; Min, S. K. \& Kim, E. C. Successful reconstruction of $15-\mathrm{cm}$ segmental defects by bone marrow stem cells and resected autogenous bone graft in central hemangioma. J. Oral Maxillofac. Surg., 68(1):188-94, 2010.
Li, T. Y.; Shu, C.; Wong, C. H.; Lo, P. S.; Zhu, H.; Lau, M. C.; Chan, M. Y.; Tsang, L. L.; Gou, Y. L.; Chung, Y. W. \& Chan, H. C. Plasticity of rat bone marrow-derived 5-hydroxytryptaminesensitive neurons: dedifferentiation and redifferentiation. Cell Biol. Int., 28(11):801-7, 2004.

Li, W. J.; Tuli, R.; Huang, X.; Laquerriere, P. \& Tuan, R. S. Multilineage differentiation of human mesenchymal stem cells in a three-dimensional nanofibrous scaffold. Biomaterials, 26(25):5158-66, 2005

Liberati, A.; Altman, D. G.; Tetzlaff, J.; Mulrow, C.; Gøtzsche, P.; Ioannidis, J. P.; Clarke, M.; Devereaux, P. J.; Kleijnen, J. \& Moher, D. The PRISMA statement for reporting systematic reviews and meta-analyses of studies that evaluate health care interventions: explanation and elaboration. Ann. Intern. Med., 151(4):W65-94, 2009.

Liu, C. K.; Jing, C. X.; Tan, X. Y.; Xu, J. \& Hu, M. Using threedimensional porous internal titanium scaffold or allogenic bone scaffold for tissue-engineering condyle as a novel reconstruction of mandibular condylar defects. J. Med. Hypotheses Ideas, 8(2):69-73, 2014.

Lohberger, B.; Payer, M.; Rinner, B.; Bartmann, C.; Stadelmeyer, E.; Traunwieser, E.; DeVaney, T.; Jakse, N.; Leithner, A. \& Windhager, R. Human intraoral harvested mesenchymal stem cells: characterization, multilineage differentiation analysis, and 3-dimensional migration of natural bone mineral and tricalcium phosphate scaffolds. J. Oral Maxillofac. Surg., 70(10):2309-15, 2012.

Machado, E.; Fernandes, M. H. \& Gomes, P. de S. Dental stem cells for craniofacial tissue engineering. Oral Surg. Oral Med. Oral Pathol. Oral Radiol., 113(6):728-33, 2012.

Mesimäki, K.; Lindroos, B.; Törnwall, J.; Mauno, J.; Lindqvist, C.; Kontio, R.; Miettinen, S. \& Suuronen, R. Novel maxillary reconstruction with ectopic bone formation by GMP adipose stem cells. Int. J. Oral Maxillofac. Surg., 38(3):201-9, 2009.

Minguell, J.J.; Erices, A. \& Conget, P. Mesenchymal stem cells. Exp. Biol. Med. (Maywood), 226(6):507-20, 2001.

Moriscot, C.; de Fraipont, F.; Richard, M. J.; Marchand, M.; Savatier, P.; Bosco, D.; Favrot, M. \& Benhamou, P. Y. Human bone marrow mesenchymal stem cells can express insulin and key transcription factors of the endocrine pancreas developmental pathway upon genetic and/or microenvironmental manipulation in vitro. Stem Cells, 23(4):594-603, 2005.

Nakagawa, H.; Akita, S.; Fukui, M.; Fujii, T. \& Akino, K. Human mesenchymal stem cells successfully improve skin-substitute wound healing. Br. J. Dermatol., 153(1):29-36, 2005.

Navarro-Vila, C.; Ochandiano, S.; López de Atalaya, F. J.; Cuesta, M.; Acero, J.; Barrios, J. M.; Salmerón, J. I. \& Verdaguer, J. J. Reconstrucción mandibular: colgajos pediculados y microquirúrgicos. Cir. Esp., 72(5):287-96, 2002. 
Payne, K. F.; Balasundaram, I.; Deb, S.; Di Silvio, L. \& Fan, K. F. Tissue engineering technology and its possible applications in oral and maxillofacial surgery. Br. J. Oral Maxillofac. Surg., $52(1): 7-15,2014$.

Park, J. S.; Kim, B. C.; Kim, B. H.; Lee, J. I. \& Lee, J. Up-andcoming mandibular reconstruction technique with autologous human bone marrow stem cells and iliac bone graft in patients with large bony defect. J. Craniofac. Surg., 26(8):e718-20, 2015.

Pogrel, M. A.; Podlesh, S.; Anthony, J. P. \& Alexander, J. A comparison of vascularized and nonvascularized bone grafts for reconstruction of mandibular continuity defects. J. Oral Maxillofac. Surg., 55(11):1200-6, 1997.

Ratajczak, M. Z.; Kucia, M.; Majka, M.; Reca, R. \& Ratajczak, J. Heterogeneous populations of bone marrow stem cells--are we spotting on the same cells from the different angles? Folia Histochem. Cytobiol., 42(3):139-46, 2004.

Rickert, D.; Sauerbier, S.; Nagursky, H.; Menne, D.; Vissink, A. \& Raghoebar, G. M. Maxillary sinus floor elevation with bovine bone mineral combined with either autogenous bone or autogenous stem cells: a prospective randomized clinical trial. Clin. Oral Implants Res., 22(3):251-8, 2011.

Rojas, M.; Xu, J.; Woods, C. R.; Mora, A. L.; Spears, W.; Roman, J. \& Brigham, K. L. Bone marrow-derived mesenchymal stem cells in repair of the injured lung. Am. J. Respir. Cell Mol. Biol., 33(2):145-52, 2005.

Sándor, G. K.; Numminen, J.; Wolff, J.; Thesleff, T.; Miettinen, A.; Tuovinen, V. J.; Mannerström, B.; Patrikoski, M.; Seppänen, R.; Miettinen, S.; Rautiainen, M. \& Öhman, J. Adipose stem cells used to reconstruct 13 cases with cranio-maxillofacial hardtissue defects. Stem Cells Transl. Med., 3(4):530-40, 2014.

Sándor, G. K.; Tuovinen, V. J.; Wolff, J.; Patrikoski, M.; Jokinen, J.; Nieminen, E.; Mannerström, B.; Lappalainen, O. P.; Seppänen, R. \& Miettinen, S. Adipose stem cell tissue-engineered construct used to treat large anterior mandibular defect: a case report and review of the clinical application of good manufacturing practice-level adipose stem cells for bone regeneration. J. Oral Maxillofac. Surg., 71(5):938-50, 2013.

Shayesteh, Y. S.; Khojasteh, A.; Soleimani, M.; Alikhasi, M.; Khoshzaban, A. \& Ahmadbeigi, N. Sinus augmentation using human mesenchymal stem cells loaded into a beta-tricalcium phosphate/hydroxyapatite scaffold. Oral Surg. Oral Med. Oral Pathol. Oral Radiol. Endod., 106(2):203-9, 2008.

Shanti, R. M.; Li, W. J.; Nesti, L. J.; Wang, X. \& Tuan, R. S. Adult mesenchymal stem cells: biological properties, characteristics, and applications in maxillofacial surgery. J. Oral Maxillofac. Surg., 65(8):1640-7, 2007.

Soltan, M.; Smiler, D. G. \& Gailani, F. A new "platinum" standard for bone grafting: autogenous stem cells. Implant Dent., 14(4):322-7, 2005.

1538
Tollemar, V.; Collier, Z. J.; Mohammed, M. K.; Lee, M. J.; Ameer, G. A. \& Reid, R. R. Stem cells, growth factors and scaffolds in craniofacial regenerative medicine. Genes Dis., 3(1):56-71, 2016.

Turhani, D.; Weissenböck, M.; Watzinger, E.; Yerit, K.; Cvikl, B.; Ewers, R. \& Thurnher, D. Invitro study of adherent mandibular osteoblast-like cells on carrier materials. Int. J. Oral Maxillofac. Surg., 34(5):543-50, 2005.

van Hout, W. M.; Mink van der Molen, A. B.; Breugem, C. C.; Koole, R. \& Van Cann, E. M. Reconstruction of the alveolar cleft: can growth factor-aided tissue engineering replace autologous bone grafting? A literature review and systematic review of results obtained with bone morphogenetic protein-2. Clin. Oral Investig., 15(3):297-303, 2011.

Warnke, P. H.; Wiltfang, J.; Springer, I.; Acil, Y.; Bolte, H.; Kosmahl, M.; Russo, P. A.; Sherry, E.; Lützen, U.; Wolfart, S. \& Terheyden, $\mathrm{H}$. Man as living bioreactor: fate of an exogenously prepared customized tissue-engineered mandible. Biomaterials, 27(17):3163-7, 2006.

Zamiri, B.; Shahidi, S.; Eslaminejad, M. B.; Khoshzaban, A.; Gholami, M.; Bahramnejad, E.; Moghadasali, R.; Mardpour, S. \& Aghdami, N. Reconstruction of human mandibular continuity defects with allogenic scaffold and autologous marrow mesenchymal stem cells. J. Craniofac. Surg., 24(4):1292-7, 2013.

Zhang, Z. Y.; Teoh, S. H.; Hui, J. H.; Fisk, N. M.; Choolani, M. \& Chan, J. K. The potential of human fetal mesenchymal stem cells for off-the-shelf bone tissue engineering application. Biomaterials, 33(9):2656-72, 2012.

Zhao, L.; Weir, M. D. \& Xu, H. H. An injectable calcium phosphatealginate hydrogel-umbilical cord mesenchymal stem cell paste for bone tissue engineering. Biomaterials,31(25):6502-10, 2010.

Zuk, P. A. Tissue engineering craniofacial defects with adult stem cells? Are we ready yet? Pediatr. Res., 63(5):478-86, 2008.

\author{
Correspondencia a: \\ Juan Pablo Alister Herdener \\ División de Cirugía Oral y Maxilofacial \\ Facultad de Odontología \\ Universidad de La Frontera \\ Manuel Montt 115 \\ Temuco, \\ CHILE
}

Email: juan.alister@ufrontera.cl

Recibido : 01-07-2016

Aceptado: 24-10-2016 